\title{
REVIEW: APPLICATION OF MAGNETIC SOLID-PHASE EXTRACTION (MSPE) IN VARIOUS TYPES OF SAMPLES
}

\section{IKE SUSANTI, HOLIS ABDUL HOLIK}

Department of Pharmaceutical Analysis and Medicinal Chemistry, Faculty of Pharmacy/Universitas Padjadjaran, Sumedang 45363, (West Java) Indonesia

*Email: holis@unpad.ac.id

Received: 05 Aug 2021, Revised and Accepted: 15 Oct 2021

\section{ABSTRACT}

This review aimed to inform about the magnetic nanoparticle functionalization and solid magnetic phase extraction application to separate analytes in various types of samples. The review was conducted by analyzing several articles published in 2010 until 2021 obtained through search engines, such as Science Direct, Google Scholar and PubMed, using the keyword "magnetic phase extraction" and "magnetic nanoparticle". The magnetic nanoparticle can be functionalized with organic, inorganic, and metal-organic framework compounds to obtain good selectivity and extraction capability. The Magnetic Solid Phase Extraction (MSPE) can be applied to separate analytes in biological, food, environmental samples. The MSPE can be used in various biological, food, and environmental samples resulting in high enrichment factor value, good recovery, and the magnetic adsorbent has excellent reusability.

Keywords: Adsorbent, Magnetic nanoparticle, Magnetic solid-phase extraction

(C) 2021 The Authors. Published by Innovare AcademicSciences Pvt Ltd. Thisis an open access articleunder the CCBYlicense (https://creativecommons.org/licenses/by/4.0/) DOI: https://dx.doi.org/10.22159/ijap.2021.v13s4.43817 Journal homepage: https://innovareacademics.in/journals/index.php/ijap

\section{INTRODUCTION}

Sample preparation is one of the essential steps in complex matrix analysis. The correct sample preparation method will ensure the analyte's sensitivity to match the instrument's detection limit and increase the selectivity by eliminating unnecessary and interfering compounds in the matrix [1]. One of the steps in sample preparation is the extraction process. Solid-phase extraction (SPE) is one of the extraction methods that has the advantage of simultaneous or selective to a substance because different adsorbents interact with different substances [2]. However, this SPE technique has several disadvantages due to adsorbent packings, such as blockage of the sorbent and high pressure. One method that can be used to overcome this problem is to use the Magnetic Solid Phase Extraction (MSPE) technique [3].

In the MSPE technique, a magnetic adsorbent was used to adsorb the target analyte (extraction process). The extraction process can be done by suspending magnetic adsorbents with a sample solution by mixing [4]. After the extraction process, the magnetic adsorbent is separated using an external magnet (a separation process). Separation is carried out without the need for filtration and centrifugation processes [5]. Then, the analyte was eluted from the magnetic adsorbent by adding the appropriate solvent (elution process), and the magnetic separation is performed to collect the liquid phase containing an analyte. The magnetic adsorbent that has been used for extraction can be directly reused for other sample batches [6]. Fig. 1 shows the schematic of MSPE. Unlike the SPE method, the magnetic adsorbents are directly dispersed in the sample solution increasing the interfacial area between adsorbent and target analyte and eliminating column blockage problem. Furthermore, analyte isolation is simple and convenient because magnetic adsorbent is immediately separated from analyte solution by applying external magnetic [7].

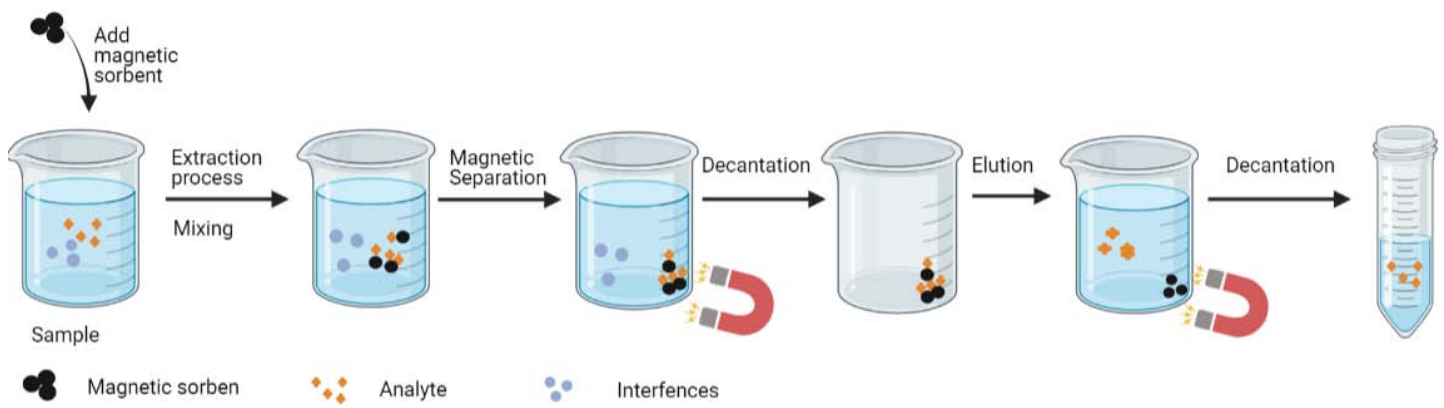

Fig. 1: Schematic of MSPE (created in BioRender.com)

Similar to SPE, the extraction process in MSPE is based on an interaction between the analyte and functional group of adsorbents through hydrogen bonding, van der Waals forces, dipole-dipole, electrostatic force, etc. [8,9]. Therefore, the magnetic nanoparticle as magnetic core in magnetic adsorbent has been functionalized with other materials to obtain good selectivity and extraction capability. The magnetic nanoparticle can be functionalized with organic, inorganic, and metal-organic framework compounds [1012]. At present, there are many developments in magnetic solidphase extraction, including the development of MSPE for the separation of active substances in biological samples [13], purification in extracts [4], pesticides in fruit and vegetables [14]. This review aims to inform about the magnetic nanoparticle functionalization and an application of solid magnetic phase extraction to separate analytes in various types of samples.

\section{METHOD}

This review was obtained by analyzing several articles obtained through search engines, such as ScienceDirect, Google Scholar and PubMed 
published in 2010 until 2021. The article was found using the keyword "magnetic solid-phase extraction" and "magnetic nanoparticles". The pre-proof journal and not indexed by Scopus were excluded.

\section{Magnetic nanoparticle synthesis (MNPs)}

Magnetic adsorbents have an essential role in MSPE. Materials commonly used as magnetic materials in adsorbents are iron (Fe), magnetite $\left(\mathrm{Fe}_{3} \mathrm{O}_{4}\right)$, maghemite $\left(\gamma-\mathrm{Fe}_{2} \mathrm{O}_{3}\right)$, cobalt $(\mathrm{Co})$, nickel $(\mathrm{Ni})[15-$ 18]. Moreover, iron oxide is often used in the synthesis of magnetic adsorbents. This iron oxide has high magnetic properties and has low toxicity [19]. Synthesis of magnetic nanoparticles is carried out using chemical co-precipitation, pyrolysis, solvothermal synthesis, and micro-emulsion methods [20-23].

The chemical co-precipitation method is simple and is usually used to prepare magnetic adsorbents because of the short reaction time, simple processing, low prices, and ease of manufacture on an industrial scale [24]. In the co-precipitation method, a solution consisting of $\mathrm{FeCl}_{3} .6 \mathrm{H}_{2} \mathrm{O}$ and $\mathrm{FeCl}_{2} .4 \mathrm{H}_{2} \mathrm{O}$ in water under a nitrogen atmosphere and distilled at a temperature of $70-85^{\circ} \mathrm{C}$ followed the addition of alkaline solution. A precipitate from magnetic nanoparticles is generated and then separated by an external magnet [20]. But in this method, the deposition of metal ions is not uniform, and synthetic materials are usually easy to agglomerate and usually have a broad particle size distribution [3].

Pyrolysis is the method that involves the decomposition of iron compounds at high temperatures. Iron is placed in a calcined tube furnace from $300-700^{\circ} \mathrm{C}$ under nitrogen gas flow at a heating rate of $5{ }^{\circ} \mathrm{C} / \mathrm{min}$ (pyrolytic in situ) [21]. Another synthesis method is solvothermal methods. It has been used to synthesize several types of nanoparticles with liquid-solid reactions under different hydrothermal conditions. The crucial factors in the synthesis using this method are temperature and reaction time. The use of microwaves in this analysis can help optimize the time used [22]. The micro-emulsion method used also is used to synthesis MNPs. The micro-emulsion method consisted of surfactant, cosurfactant, oil and metal salt solution. The metal salt solution was added to the mixture solution of surfactant, cosurfactant, oil. The metal compound was dispersed in the water-oil system under the action of surfactant. Then, the alkali solution as precipitating agent is added to form the MNPs [23]. The final nanoparticles are strongly influenced by the proportions of the many components that make up the microemulsion. The ratio of the water phase to surfactant could influence the particle size of MNPs [25]. Various methods can carry out the synthesis of MNPs. Still, several factors need to be considered, such as $\mathrm{pH}$, time reaction, temperature and ratio of component that consisted, to produce a uniform MNPs particle size, range of particle distribution is narrow and no aggregation.

\section{Magnetic nanoparticle functionalization}

Magnetic nanoparticles must be functionalized to produce magnetic adsorbents that can extract analytes in the sample based on their interaction. The interaction between adsorbent and analyte can occur through $\pi-\pi$ interaction, dipole-dipole interaction, hydrogen bonding, hydrophobic interaction [10,26-28]. The magnetic nanoparticle can be functionalized with an organic compound, inorganic compound and metal-organic framework [27-34]. Table 1 provides the summary of magnetic nanoparticle functionalization.

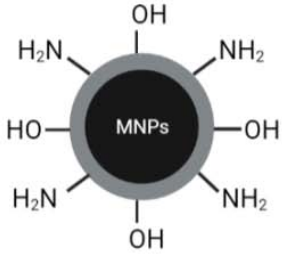

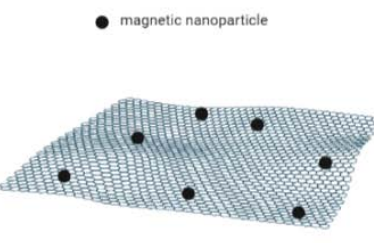

b1

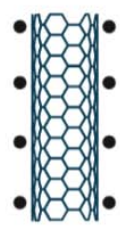

b2

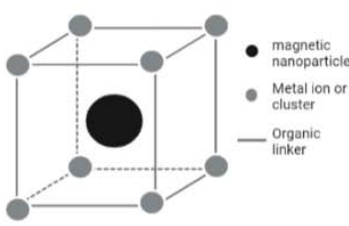

$c$

Fig. 2: Example for structure of magnetic nanoparticle functionalization. a) magnetic nanoparticle functionalization with polydopamine. b1) Graphene oxide-magnetic nanoparticle, b2) magnetic carbon nanotube. c) Magnetic Nanoparticle Functionalization with MetalOrganic Frameworks (created in BioRender.com)

\section{Magnetic nanoparticle functionalization with organic compounds}

$\beta$-cyclodextrin is one of the materials used in the functionalization of MNs because it has selectivity and good affinity. $\beta$-cyclodextrin (CD) is an oligosaccharide consisting of seven D-glucopyranose units connected by $\beta$-1,4-glycosidic bonds [35]. $\beta$-cyclodextrin has a polar hydrophilic outer shell because it is rich in hydroxyl $(\mathrm{OH})$ groups and has a relatively hydrophobic cavity that can encapsulate hydrophobic molecules [36]. Zhang et al. [29] developed the $\mathrm{Fe}_{3} \mathrm{O}_{4} @ \mathrm{fTiO}_{2}-\mathrm{CMCD}$ adsorbent with the grafting method to determine chlorobenzene levels. $\mathrm{TiO} 2$ was used to coat the $\mathrm{Fe}_{3} \mathrm{O}_{4}$ to provide surface modification to sundry functional groups. Then, the surface of $\mathrm{Fe}_{3} \mathrm{O}_{4} @ \mathrm{fTiO}_{2}$ was functionalized with carboxymethyl- $\beta$ cyclodextrin (CMCD) to produce $\mathrm{Fe}_{3} \mathrm{O}_{4} @ \mathrm{fTiO}_{2}$ - $\mathrm{CMCD}$. The CMCD was chosen because it has a hydrophobic cavity that allows the interaction of adsorbent with chlorobenzene. Therefore, the adsorption capacity and selectivity of $\mathrm{Fe}_{3} \mathrm{O}_{4} @ \mathrm{fTiO}_{2}-\mathrm{CMCD}$ have increased. The development of CD-modified MNs was also carried out by Zhang et al.[28]. Graphene oxide- $\beta$-cyclodextrin (MGO-CD) is synthesized by aromatic nucleophilic substitution of CD hydroxyl groups and magnetic graphene oxide (MGO) with tetrafluoroterephthalonitrile linker for analysis of carbamazepine in serum. The interaction mechanism between the MGO-CD and analyte is hydrophobic interaction. Another interaction between MGO-CD and carbamazepine is hydrogen bonding because the $\mathrm{OH}$ groups of $\mathrm{CD}$ interacted with the amide group of carbamazepine [28].
Dopamine is a substance that can self-polymerize at $25{ }^{\circ} \mathrm{C}$ to form a polydopamine (PDA) shell on the surface of various types of materials [26]. When the nanoparticles are coated with PDA, the nanoparticles become more stable. They have good dispersibility in the aqueous phase solution and the interaction of $\pi-\pi$ with molecular targets. PDA-coated nanoparticles are usually used to absorb or remove contaminants in the water $(19,20)$. Li et al. [27] synthesized magnetic nanoparticles coated with polydopamine ( $\left.\mathrm{Fe}_{3} \mathrm{O}_{4} @ \mathrm{PDA}\right)$ by solvothermal reaction and dopamine's selfpolymerization as a magnetic sorbent for extracting the phenolic compound such as 2,4,6-tribromophenol, bisphenol A, tetrabromobisphenol A, and (S)-1,1'-bi-2-naphthol in environmental water samples. The interaction between $\mathrm{Fe}_{3} \mathrm{O}_{4} @ P D A$ and these phenolic compounds has dominated with hydrophobic interaction. However, the $\pi-\pi$ stacking and hydrogen bonding interactions also occurred in this interaction [27]. Zhu et al. [10] also synthesized $\mathrm{Fe}_{3} \mathrm{O}_{4} @ P D A$ for the analysis of glimepiride compounds in dog plasma. $\mathrm{Fe}_{3} \mathrm{O}_{4} @ P D A$ can be synthesized by the grafting method and produces high yields to be applied to analyze large samples. Theoretically, the PDA layer can bind aromatic rings and amino groups present in the glimepiride structure in the presence of $\pi-\pi$ interactions and hydrogen bonds [10].

Hemimicelles/admicelles SPE is a technique that used a single layer (monolayer) of surfactant, which adsorbs on oppositely charged materials (hemimicelles) and the surfactant bilayer (admicelles) as a 
sorbent. The surfactants' hydrocarbon chains can provide hydrophobic interactions with hydrophobic analytes, while the polar groups will adsorb ionic analytes through electrostatic interactions or hydrogen bonds [39]. Liu et al. [30] synthesized Hemmimicelles/ admicelles on graphene sheet (MG) magnets to extract various organic pollutants. MG sheets can be positively or negatively charged depending on the $\mathrm{pH}$ of the solution, which allows extraction under various conditions. Cetyltrimethylammonium Bromide (CTAB) is a surfactant to form micelles and provides a cationic mode. They found that the functionalization MG with CTAB (MG-CTAB) sorbent had good extraction capabilities and good selectivity for polyfluorohydrocarbons (PFAs) and alkylphenol than direct extraction with MG sorbent. The result showed that CTAB hemimicelles/admicelles allow hydrophobic and chains-chain interaction to increase due to the formation of a hydrophobic bond site by hemmicicelles/admicelles. For the anionic mode, sodium dodecyl sulfate (SDS) is used to form micelles. The analyte used is alkyl trimethylammonium. In the SDS presence, the extraction efficiency of the analyte increases due to the strong interaction between cationic surfactants and SDS hemimicelles/admicelles [30].

\section{Magnetic nanoparticle functionalization with inorganic compounds}

One of the compounds used for the functionalization of magnetic nanoparticles is graphene and carbon nanotubes. Graphene has a twodimensional sp2-bonded carbon layer arranged in a honeycomb lattice. Graphene oxide (GO) is an essential derivative of graphene because of its specific surface area and good physicochemical properties. GO can effectively absorb polycyclic aromatic hydrocarbons through $\pi-\pi$ interactions and hydrophobic interactions [40]. GO can be enriched with an oxygen-containing functional group in the form of a hydroxyl $(-\mathrm{OH})$ and epoxide (C-O) group in the basal plane, as well as a carbonyl group $(\mathrm{C}=0)$ and a carboxyl $(-\mathrm{COOH})$ group placed on the GO edge [41]. Pashaei et al. [31] synthesized the GO- $\mathrm{Fe}_{3} \mathrm{O}_{4}$ for pre-concentration terazosin hydrochloride using the magnetic-dispersive solid phase extraction method in the human plasma sample. GO was synthesized using the modified Hummers method. In this method, the potassium permanganate $\left(\mathrm{KMnO}_{4}\right)$ is used as an oxidizing and intercalating agent while the hydrogen peroxide $\left(\mathrm{H}_{2} \mathrm{O}_{2}\right)$ is added to remove the excess of $\mathrm{KMnO}_{4}$.

The $\mathrm{GO}-\mathrm{Fe}_{3} \mathrm{O}_{4}$ was synthesized by the impregnation method. The $\mathrm{Fe}_{3} \mathrm{O}_{4}$ were protonated to obtain a positive charge by dispersing in nitric acid $\left(\mathrm{HNO}_{3}\right)$. The protonated $\mathrm{Fe}_{3} \mathrm{O}_{4}$ was added to the exfoliated GO that resulted by dispersing and ultrasonication the graphite oxide in deionized water. The mixture was stirred and centrifugated to form uniform dispersion. The mixture was centrifugated and separated from the supernatant use external magnetic to collect the GO- $\mathrm{Fe}_{3} \mathrm{O}_{4}$ [31]. The sample $\mathrm{pH}$ influences the interaction between terazosin and $\mathrm{GO}-\mathrm{Fe}_{3} \mathrm{O}_{4}$ because it can change the terazosin form (molecule or ionic form) in an aqueous solution and the density of the surface's sorbent. The extraction efficiency of terazosin significantly increased when the $\mathrm{pH}$ solution was increased from 2 to 5. However, the extraction efficiency of terazosin progressively decreased when the $\mathrm{pH}$ solution was higher than 5. In a lower $\mathrm{pH}$ solution, the iron oxide was dissolved, and the stability of $\mathrm{GO}-\mathrm{Fe}_{3} \mathrm{O}_{4}$ decrease that causes the electrostatic repulsion between the $\mathrm{Fe}_{3} \mathrm{O}_{4}$ and the GO. Causes the extraction efficiency to be low in strong acid solution or lower $\mathrm{pH}$. When the $\mathrm{pH}$ solution is 5.0 , the interaction between terazosin and $\mathrm{GO}-\mathrm{Fe}_{3} \mathrm{O}_{4}$ was optimal. In this condition, the stability of $\mathrm{GO}-\mathrm{Fe}_{3} \mathrm{O}_{4}$ is high, and the negative charge such as- $\mathrm{COOH}$ and-OH group of GO functional group will interact optimally with protonated terazosin. In higher $\mathrm{pH}$ (strongly alkaline), the terazosin exists in molecule form ( $\mathrm{pKa}=7.1)$, and the $\mathrm{GO}-\mathrm{Fe}_{3} \mathrm{O}_{4}$ has a negative charge which causes the interaction week and the extraction efficiency of terazosin was low [31].

Lu et al. [11] also synthesized $\mathrm{GO}-\mathrm{Fe}_{3} \mathrm{O}_{4}$ nanocomposite as a sorbent for MSPE to extract psychoactive drugs in the urine sample. GO$\mathrm{Fe}_{3} \mathrm{O}_{4}$ was synthesized by co-precipitation of $\mathrm{Fe}^{2+}$ and $\mathrm{Fe}^{3+}$ in the GO dispersion solution under ultrasonic conditions. $\mathrm{Fe}_{3} \mathrm{O}_{4}$ nanoparticles bind to the GO sheet with the help of a carboxylic group. Lu et al. [11] observed the morphological shape of $\mathrm{GO}-\mathrm{Fe}_{2} \mathrm{O}_{3}$ using the TEM instrument. $\mathrm{GO}$ sheet has a large surface area, and $\mathrm{Fe}_{3} \mathrm{O}_{4}$ will bind to the GO sheet surface. Some $\mathrm{Fe}_{3} \mathrm{O}_{4}$ nanoparticles are aggregated, most likely due to their small size, around 2-10 nm [11]. This study showed the $\mathrm{GO}-\mathrm{Fe}_{3} \mathrm{O}_{4}$ has an excellent performance in extracting some psychoactive drugs. The sorbent can be reused multiple times to extract the sample without losing its extraction capabilities [11].

Carbon nanotubes can be combined with magnetic nanoparticles easily through covalent bonds or non-covalent interactions such as electrostatic interactions and charge transfer. Carbon nanotube has the advantage of physicochemical properties, including good stability and mechanical strength, larger surface area, functionalized, hydrophobicity, and delocalized $\pi$-electron system [5]. Based on the location of magnetic nanoparticles on carbon nanotubes, magnetic carbon nanotubes (MCNTs) can be classified into two categories, namely magnetic nanoparticles located on the surface of carbon nanotubes and magnetic nanoparticles located in the cavities of carbon nanotubes [1]. Dimension of carbon nanotube can affect to pre-concentration and adsorption performance of the MCNT. Based on that, El-Sheikh et al. [42] synthesize the MCNTs with various dimensions of carbon nanotube and various ratios of carbon nanotube and magnetite. In this study, magnetite and carbon nanotube (Mag: CNT) ratios used were 1:2; 1:1; and 2:1. The result showed that increasing the ratio of Mag: CNT to 2:1 would decrease the recovery of NSAIDs. However, the recovery of NSAIDs for sorbent with the ratio of Mag: CNT were 1:1 and 1:2 have a similar result. To investigate the effect of CNT dimension on adsorption performance, El-Sheikh et al. [42] used the CNT with different lengths and diameters, $10-100 \mathrm{~nm}$ in diameter and $1-15 \mu \mathrm{m}$ in length. MCNT with a larger diameter $(60-100 \mathrm{~nm})$ results in good adsorption for NSAIDs, while the length of MNCT was an insignificant effect on adsorption NSAIDs [42]. Li et al. [32] synthesis magnetic sorbent for dispersive micro solid-phase extraction with two kinds of CNT, such as magnetic single-walled carbon nanotubes (Mg-SWCNTs) using single-walled carbon nanotubes with 0.7-1.3 $\mathrm{nm}$ in diameter and $1 \mu \mathrm{m}$ in length; and magnetic multi-walled carbon nanotubes (Mg-MWCNTs) using multi-walled carbon nanotubes with $110-170 \mathrm{~nm}$ in diameter and 5-9 $\mu \mathrm{m}$ in length. The analyte that will extract in biological samples was cyanide metabolite, 2-aminothiazoline-4-carboxylic acid. The average recovery of 2-aminothiazoline-4-carboxylic acid using Mg-SWCNTs and Mg-MWCNTs as a sorbent showed that no significant difference. However, in this study, the Mg-MWCNTs were chosen as an adsorbent to extract 2-aminothiazoline-4-carboxylic acid because the variation in the average recovery and its cost were lower [32].

Moreover, magnetic nanoparticles can be modified by the addition of inorganic compounds such as silica. In general, silica can be used to overcome the aggregate of $\mathrm{Fe}_{3} \mathrm{O}_{4}$ because silica compounds have inert properties and can weaken the bipolar interaction of particles and make $\mathrm{Fe}_{3} \mathrm{O}_{4}$ nanoparticles stable [43]. Tetraethyl orthosilicate (TEOS) is one of the materials that is often used in synthesizing silica. Mashhadizadeh and Diva [43] synthesized $\mathrm{Fe}_{3} \mathrm{O}_{4}$ nanoparticles with a silica coating modified with 3-mercapto propionic acid to separate $\mathrm{Al}^{3+}$ and $\mathrm{Cr}^{3+}$. 3-mercapto propionic acid has a carboxyl (oxygen-donating atom) functional group with suitable characteristics to form stable complexes with metal ions such as $\mathrm{Al}^{3+}$ and $\mathrm{Cr}^{3+}$. Alkyl modification of silanol groups can be applied in the pretreatment of some hydrophobic analytes because of the lipophilic nature of these compounds [44]. Caon et al. [45] synthesized core-shell magnetic nanoparticles coated with silica with a hydrophobically modified surface for extracting triclosan. This study used three kinds of magnetic core $\left(\mathrm{CoFe}_{2} \mathrm{O}_{4}, \gamma-\mathrm{Fe}_{2} \mathrm{O}_{3}\right.$ and $\mathrm{MnFe}_{2} \mathrm{O}_{4}$ ). These cores were coated respectively and then functionalized with organosilane octadecyltrimethoxysilane. The result showed that CoFe204@SiO2-C18, $\gamma$-Fe203@SiO2-C18 and $\mathrm{MnFe204@SiO2-C18} \mathrm{were} \mathrm{insignificantly} \mathrm{different} \mathrm{in} \mathrm{adsorption}$ capacity, but the magnetic content of $\mathrm{CoFe}_{2} \mathrm{O}_{4} @ \mathrm{SiO} 2-\mathrm{C} 18$ was higher than other. The higher magnetic content showed the adsorbent would more easily be separated using an external magnetic field from the supernatant [45].

Magnetic nanoparticle functionalization with metal-organic frameworks

Metal-organic frameworks (MOFs) are constructed with ligands and metal ions through the coordinate bond. MOF has several 
advantages such as easy composition (metal ions and organic ligands), has a specific surface area, has a wide pore size range [12], can be modified, and has good chemical and thermal stability. Based on these, the MOF has good potential in separation analyte in the sample [46]. MOF does not have magnetic properties, so there needs to be a procedure to add magnetic properties to MOF, including direct MOF magnetization. Zhang et al. [33] synthesized $\mathrm{Fe}_{3} \mathrm{O}_{4} @ \mathrm{SiO}_{2} @ \mathrm{UiO}-66$ by facile hydrothermal synthesis. First, the $\mathrm{Fe}_{3} \mathrm{O}_{4}$ was coated with $\mathrm{SiO}_{2}\left(\mathrm{Fe}_{3} \mathrm{O}_{4} @ \mathrm{SiO}_{2}\right)$ to protect it from degradation and further functionalization. Then the $\mathrm{Fe}_{3} \mathrm{O}_{4} @ \mathrm{SiO}_{2}$ was functionalized with an organosilane, 3-Aminopropyl)triethoxysilane. To produce $\mathrm{Fe}_{3} \mathrm{O}_{4} @ \mathrm{SiO}_{2} @ U i \mathrm{O}-66$, functionalized $\mathrm{Fe}_{3} \mathrm{O}_{4} @ \mathrm{SiO}_{2}$ was added into a mixed solution containing $\mathrm{N}$, N-dimethylformamide, terephthalic acid, and $\mathrm{ZrCl}_{4}$ (UiO66) then stir the solution at $130^{\circ} \mathrm{C}$ in an oil bath for $3 \mathrm{~h}$. $\mathrm{Fe}_{3} \mathrm{O}_{4} @ \mathrm{SiO}_{2} @ U i \mathrm{U}-66$ was used to extract domoic acid. To investigate the effect of MOF (UiO-66) on the extraction capability, the $\mathrm{Fe}_{3} \mathrm{O}_{4} @ \mathrm{SiO}_{2} @ U i 0-66$ and $\mathrm{Fe}_{3} \mathrm{O}_{4} @ \mathrm{SiO}_{2}$ were evaluated. The result showed that the $\mathrm{Fe}_{3} \mathrm{O}_{4} @ \mathrm{SiO}_{2} @$ @iO-66 could extract a higher concentration of domoic acid than $\mathrm{Fe}_{3} \mathrm{O}_{4} @ \mathrm{SiO}_{2}$. It indicates that the UiO-66 has a role key on the extraction capability because the interaction between UiO-66 and domoic acid may depend on the affinity of the negatively charged carboxylic acid group toward the vacant orbital of the metal ion $\left(\mathrm{Zr}^{4+}\right)$. The high adsorption capability is aided by the larger number of binding site $\left(\mathrm{Zr}^{4+}\right)$ and high surface area given by UiO-66 [33].

Huo and Yan [34] synthesized $\mathrm{Fe}_{3} \mathrm{O}_{4} @ \mathrm{SiO}_{2} @ \mathrm{MIL}-101$ sorbent using in situ magnetizations. The $\mathrm{Fe}_{3} \mathrm{O}_{4} @ \mathrm{SiO}_{2}$ and MIL-101 were synthesized separately. The MIL-101 was synthesized from a mixture of $\mathrm{Cr}\left(\mathrm{NO}_{3}\right)_{3} .9 \mathrm{H}_{2} \mathrm{O}$, terephthalic acid, and $\mathrm{HCl}$ in the water at $220^{\circ} \mathrm{C}$. Fe304@SiO2, MIL-101, and standard solution of polycyclic aromatic hydrocarbon or sample were placed in the same vial to carry out the extraction. Then the mixture was ultrasonication for 20 min to disperse the $\mathrm{Fe}_{3} \mathrm{O}_{4} @ \mathrm{SiO}_{2}$ and MIL-101 and for magnetization of MIL-101 to form $\mathrm{Fe}_{3} \mathrm{O}_{4} @ \mathrm{SiO}_{2} @ \mathrm{MIL}-101$ for the simultaneous extraction of polycyclic aromatic hydrocarbon [34]. The $\mathrm{Fe}_{3} \mathrm{O}_{4} @ \mathrm{SiO}_{2}$ sorbent hardly extracted polycyclic aromatic hydrocarbon; therefore, the MIL-101 has an important role in extracting the polycyclic aromatic hydrocarbon. This study investigates the effect of the amount of MIL-101 on extraction efficiency. When the amount of MIL-101 was increased from 0 to $0.6 \mathrm{mg}$, the extraction efficiency increased significantly, revealing MIL-101's outstanding enrichment ability. When the amount of MIL-101 was increased from 0.6 to 1.0 $\mathrm{mg}$, the extraction efficiency reduced somewhat or even declined, indicating that too much MIL 101 without magnetic modification adsorbed caused a portion of polycyclic aromatic hydrocarbon could not be collected by magnetic separation [34].

Table 1: Example compound for functionalization of magnetic nanoparticles

\begin{tabular}{|c|c|c|}
\hline Magnetic sorbent & Compound & Ref \\
\hline \multirow[t]{3}{*}{ Magnetic nanoparticle functionalized with organic compounds } & $\beta$-cyclodextrin & {$[29,28]$} \\
\hline & Dopamine & {$[10,27]$} \\
\hline & Surfactant & [30] \\
\hline \multirow[t]{3}{*}{ Magnetic nanoparticles functionalized with inorganic compounds } & Graphene Oxide & [11] \\
\hline & Carbon nanotube & [32] \\
\hline & Silica & [45] \\
\hline Magnetic nanoparticle functionalized with Metal-Organic & UiO-66 & [33] \\
\hline Framework & MIL-101 & [34] \\
\hline
\end{tabular}

\section{Application of mspe in varoius sample}

MSPE is an extraction method that has easy and rapid sample extraction. This method was developed to overcome the drawback of SPE, such as packing of material and time-consuming $[39,11]$. Table 2 provides a summary of the application of MSPE to extract analytes in various samples.

\section{MSPE application in biological samples}

MSPE can be used as an alternative to SPE and can be used as an enrichment procedure and separation of analytes from samples with complex matrices using a magnetic sorbent. External magnets can easily separate MPSE target analysis as a sign of centrifugation or filtration [5]. Biological samples are samples that have a very complex matrix. Biological sample analysis is usually carried out to monitor drugs with a narrow therapeutic index [48], looking for users of psychoactive drugs, such as heroin and morphine [11], measuring metal levels in urine due to exposure to pollution or from food and beverages [49].

Lu et al. [11] developed MSPE using a magnetic modification of nanoparticles with graphene oxide $\left(\mathrm{GO}-\mathrm{Fe}_{3} \mathrm{O}_{4}\right)$ to analyse morphine, 6-monoacetylmorphine, amphetamine, methamphetamine, codeine, cocaine, dolantin, and benzoylecgonine in urine samples. Then the analytes were measured using UHPLC-MS/MS instrument. According to the optimization results, the extraction process reached the equilibrium point at $15 \mathrm{~min}$. This rapid extraction is due to the large surface contact between the target analyte and GO$\mathrm{Fe}_{3} \mathrm{O}_{4}$. Desorption is an essential process in MSPE analysis. The solvent used is a $3 \mathrm{ml}$ methanol solution with $10 \%$ ammonia with a desorption time of $10 \mathrm{~min}$ [11]. From the validation method results using MSPE, the LOD values were obtained with a range of 0.02-0.2 $\mu \mathrm{g} / \mathrm{l}$, and LOQ $0.05-0.5 \mu \mathrm{g} / \mathrm{l}$, the recovery obtained was around $80.4 \%-105.50 \%$ with an RSD value of $2.7 \%-13.7 \%$. Compared with other pretreatment methods such as SPE, liquid-liquid extraction, dispersive liquid-liquid microextraction (DLLME), analysis using the MSPE extraction method provides more sensitive and inexpensive results and adsorbents that are reusable [11].
Alendronate is a drug used in the treatment of hypocalcemia. In general, alendronate is given in very small doses so that alendronate analysis has difficulty in the process of purification and detection. The lanthanide luminescence method can determine the fluorometric levels of an organic molecule, forming complexes with lanthanides. The emission of lanthanide ion chelates such as terbium chelate $\left(\mathrm{TB}^{3+}\right)$ can produce strong fluorescence with a large change in wavelength (stoke change) and a narrow emission band [50]. Niaei et al.[48] developed a modified magnetic nanoparticle sorbent with PEG-b-P(IA-co-DMAEMA) block copolymer-TB ${ }^{3+}$. The alendronate in the sample will be adsorbed and form a complex alendronate-TB ${ }^{3+}$ that can fluoresce. Urine samples spiked with an alendronate standard with a 600-1000 ppb concentration yielded a $98.9-100.8 \%$ recovery value with an RSD $\leq 4.7 \%$. While the serum samples spiked with alendronate standard with a 400-800 ppb concentration resulted in a recovery value of $97.5-102.1 \%$ with an RSD value of $4.4 \%$. The LOD value obtained from the linearity range $0.040-0.800 \mathrm{ppm}$ is $0.011 \mathrm{ppm}$. Based on these results, this method can be used as a routine analytical procedure for alendronate in biological samples because the method is accurate, precise, and has high sensitivity [48].

Tang et al. [51] analyzed sildenafil and desmethyl sildenafil (a metabolite of sildenafil) in a biological sample using magnetic sorbent with internal phenyl surface $\left(\mathrm{Fe}_{3} \mathrm{O}_{4}-\mathrm{SiO}_{2}-\mathrm{Ph}\right)$ with methylcellulose (MC) $\left(\mathrm{Fe}_{3} \mathrm{O}_{4}-\mathrm{SiO}_{2}-\mathrm{Ph}-\mathrm{MC}\right)$ to extract the analytes then determine them using HPLC. The phenyl moiety in the sorbent made it appropriate for extracting polar analytes. Methylcellulose had a lot of hydrophilic hydroxyl moiety, which self-assembled on the $\mathrm{Fe}_{3} \mathrm{O}_{4}-\mathrm{SiO}_{2}-\mathrm{Ph}$ and was expected to improve water dispersibility, which improved the extraction efficiency [51]. The $\mathrm{Fe}_{3} \mathrm{O}_{4}-\mathrm{SiO}_{2}-\mathrm{Ph}-$ $\mathrm{MC}$ was used to extract sildenafil and desmethyl sildenafil in the plasma and urine samples under optimal conditions. The result showed that the sildenafil had an excellent linearity range of 5-200 $\mathrm{ng} / \mathrm{ml}\left(\mathrm{r}^{2}=0.9972\right)$ for both the plasma and urine samples. The RSD of the intraday for sildenafil in both samples was about $0.6 \%-4.2 \%$, while the RSD of the interday for sildenafil in both samples was about $2.9-7.9 \%$. The LOD for sildenafil in plasma and urine was 0.68 
$\mathrm{ng} / \mathrm{ml}$ and $0.41 \mathrm{ng} / \mathrm{ml}$, respectively. For desmethyl sildenafil, the linearity range for plasma and urine samples was $5-400 \mathrm{ng} / \mathrm{ml}(\mathrm{r}$ $\left.\mathrm{r}^{2}=0.9959\right)$. The RSD of the intraday for desmethyl sildenafil in both samples was about $2.4 \%-8.2 \%$, while the RSD of the interday for sildenafil in both samples was about 2.93-7.5\%. The LOD for desmethyl sildenafil in plasma and urine were $0.96 \mathrm{ng} / \mathrm{ml}$ and 0.80 $\mathrm{ng} / \mathrm{ml}$, respectively [51].

Based on the studies mentioned above, MSPE method can be applied easily in biological samples with complex matrices and resulting in excellent extraction and good recovery. Moreover, the MSPE method exhibited a rapid and sensitive method for sample preparation.

\section{MSPE application on environmental samples}

Any chemical, physical, biological or radiological compound element or compound with an unfavorable influence on air, water, soil, or living organisms is considered an environmental pollutant or contamination. Environmental contaminants can come from various sources, including mining and energy exploration, fossil fuel burning, agriculture and forestry, industrial production, pharmaceutical and personal care product, etc. [52]. Shah et al. [53] synthesized magnetic sorbents by functionalization magnetic mesoporous silica by sulfonic acid for analysis of Cu (II) and Co (II) in water samples. Before the sulfonic acid functionalization was carried out, thiol functionalized magnetic mesoporous silica $\left(\mathrm{Fe}_{3} \mathrm{O}_{4} @ \mathrm{SiO}_{2} @ \mathrm{mSiO}_{2}-\mathrm{SH}\right)$ was synthesized by adding organosilane mercaptopropyl-trimethoxysilane (MPTS) and CTAB to $\mathrm{Fe}_{3} \mathrm{O}_{4} @ \mathrm{SiO}_{2}$. After that, the $\mathrm{Fe}_{3} \mathrm{O}_{4} @ \mathrm{SiO}_{2} @ \mathrm{mSiO}_{2}-\mathrm{SH}$ was dispersed in $\mathrm{H}_{2} \mathrm{O}_{2}$ to oxidized the thiol group. And then, the product was dispersed in sulphuric acid for $30 \mathrm{~min}$ and obtained sulphonic acid-functionalized magnetic mesoporous silica (MMS). This study shows that the MMS reaches equilibrium in $25 \mathrm{~min}$ at $\mathrm{pH}$ 7. The appropriate $\mathrm{pH}$ can reduce the matrix effect and increase the high adsorption efficiency. The maximum adsorption capacities are $132 \mathrm{mg} / \mathrm{g}$ and $99.1 \mathrm{mg} / \mathrm{g}$ for copper and cobalt. Shat et al. [53] investigated the effect of matrices or other metals such as $\left(\mathrm{Fe}^{3+}, \mathrm{Mn}^{2+}, \mathrm{K}^{+}\right.$and $\mathrm{Zn}^{2+}, \mathrm{Mg}^{2+}$, etc. $)$. The error generated by these interventions of metal is less than $\pm 5 \%$ (tolerance limit). Cu (II) and Co (II) detection limits reached $20 \mathrm{ng} / \mathrm{l}$ and $27 \mathrm{ng} / \mathrm{l}$. These results indicate that this sorbent can be used for efficient pre-concentration of $\mathrm{Cu}$ (II) and Co (II) from complex environmental samples [53].

Li et al. [54] synthesized magnetic adsorbent silver-based organic coordination networks ( $\left.\mathrm{Fe}_{3} \mathrm{O}_{4} @ \mathrm{Ag}-\mathrm{OCN}\right)$ for trihalomethane extraction in water samples. The $\mathrm{pH}$ conditions at synthesizing of $\mathrm{Fe}_{3} \mathrm{O}_{4} @ \mathrm{Ag}$-OCN affect the diameter of the sorbent. In alkaline conditions $(\mathrm{pH}=9)$, the diameter is below $800 \mathrm{~nm}$, while at an acidic $\mathrm{pH}=6$, the diameter is $2 \mu \mathrm{m}$ larger. At alkaline $\mathrm{pH}$, the surface area increases compared to acidic $\mathrm{pH}$, which is $172.16 \mathrm{~m}^{2} / \mathrm{g}$, which indicates that the smaller diameter correlates with the surface area where the small size can increase the adsorption of analytes [54]. The adsorption selectivity was carried out by evaluating the trihalomethane with other pollutant compounds. Pollutants with more potent hydrophobicity exhibit a higher extraction factor. Hydrophobicity shows lower solubility and tends to move from the solution to the adsorbent surface. Among the selected pollutants, trihalomethane is a more lipophilic compound that exhibits a higher extraction factor (EF). The interactions that occur are hydrogen interactions and the nature of hydrophobicity. The extraction factor of sorbents synthesized at alkaline $\mathrm{pH}$ has a higher value than that of sorbents synthesized at acidic $\mathrm{pH}(\mathrm{EF}$ in alkaline $\mathrm{pH}=1665$, and $\mathrm{EF}$ in acid $\mathrm{pH}=1216$ ) [54].

$\mathrm{Fe}_{3} \mathrm{O}_{4}$-Cys@MIL125- $\mathrm{NH}_{2}$ is a magnetic adsorbent with a titaniumbased metal-organic core framework to extract fluoroquinolones in water samples. This adsorbent has a strong magnetic response, good hydrophilicity, and good affinity for target analytes [46]. The adsorption condition was chosen at $\mathrm{pH} 7.0$ because fluoroquinolones will be converted to an intermediate form that shows good recovery due to the interaction of $\pi-\pi$ stacking on the MIL125- $\mathrm{NH}_{2}$ layer against fluoroquinolone molecules and hydrophobic effects [46]. The $\mathrm{Fe}_{3} \mathrm{O}_{4}$-Cys@MIL125- $\mathrm{NH}_{2}$ has been used to extract fluoroquinolone in tap water and river water samples. The recoveries for the spiked tap water and spiked river water were $83.8 \%-109.4 \%$ and $84.8 \%$ $108.8 \%$. The RSD was obtained lower than $8.9 \%$ for tap water sample and $0.7-8.9 \%$ for a river water sample. The result showed that the MSPE method with $\mathrm{Fe}_{3} \mathrm{O}_{4}$-Cys@MIL125- $\mathrm{NH}_{2}$ has a chance to apply for sensitive determination of fluoroquinolone in the water sample [46].

Application of the MSPE method on environmental samples resulted in good recovery and good extraction factors. Based on the abovementioned results, the MSPE method can extract various analytes, such as metals, toxic or carcinogenic substances, and pharmaceutical drugs, in environmental samples. In the extraction process using the MSPE method, $\mathrm{pH}$ can affect the interaction between the analyte and the magnetic sorbent. Therefore, it is necessary to pay attention to the $\mathrm{pH}$ used in the extraction process.

\section{MSPE application on food samples}

Contamination in food products is accidentally present or unwanted in food that can come from the environment or impact the food chain process. This contamination can be in the form of biological contamination, veterinary drug residues, pesticides, chemical contaminants, or other objects that can disturb, harm, and endanger human health [55]. In determining this contamination level, the use of MSPE in the extraction process has been developed. Mahpishanian and Hassan [56] developed $\beta$-cyclodextrin/iron oxide reduced graphene oxide hybrid nanostructure ( $\beta$-CD/MRGO) to extract organochlorine pesticides from honey samples. Organochlorine molecules will interact with $\beta$-cyclodextrin functionalized on the graphene oxide sheet. The formation of complexes and bond strength depends on the size and dimensions appropriate and the binding force between the cavities of the cyclodextrins and organochlorines as guest molecules [56]. Organochlorines are compounds that have low and moderate polarity. These hydrophobic interactions occur in the formation of complexes between cyclodextrins and organochlorines in water media. Pesticides with high $\log$ P such as dichlorodiphenyltrichloroethane (DDT), dichlorodiphenyldichloroethylene (DDE) and Dichlorodiphenyldichloroethane (DDD) can be more bound by $\beta$ cyclodextrins cavities. Some organochlorines such as heptachlor epoxide, endosulfan sulfate, dieldrin, endosulfan I and II are hydrogen acceptors because of an oxygen atom or carbonyl group their structure. Hydrogen bonds between hydrogen or carbonyl groups in organochlorines and $\mathrm{OH}$ residues on $\beta$-cyclodextrins formed $\beta$-cyclodextrin complexes with organochlorines. The extraction carried out is assisted by the vortex process, which can in an extreme way increase the contact area between the adsorbent and the analyte because the adsorbent can be uniformly dispersed in the sample solution [56].

Jia et al. [6] and Niu et al. [57] synthesized magnetic adsorbents to extract the insecticide benzoylurea in tea samples. A magnetic metalorganic framework composite adsorbent ( $\mathrm{Fe}_{3} \mathrm{O}_{4} @ \mathrm{MOF}-808$ ) has been synthesized by Jia et al. [6]. The MOF-88 is a 3D porous MOF that has been self-assembled from Zirconium (Zr) ions and trimesic acid ligands. The interaction that occurs between adsorbents and benzoylurea are $\pi-\pi$ interactions, hydrophobic interactions, and hydrogen bonds. More hydrogen bond donors will increase the formation of hydrogen bonding interactions with the compound. Hydrogen bonding occurs between the amide group of the benzoylurea and the $\mathrm{Zr}-\mathrm{O}$ site, while the $\pi-\pi$ interaction occurs between the aromatic ring of benzoylurea and the MOF-808 framework [6]. $\mathrm{Fe}_{3} \mathrm{O}_{4} @ M O F-808$ as sorbent has advantages such as simple procedure and can be reused. When the $\mathrm{Fe}_{3} \mathrm{O}_{4} @ \mathrm{MOF}-808$ was used for ten cycles (adsorption-desorption), the RSD for all analytes in the sample change less than $10.2 \%$ indicating it was a good magnetic sorbent with excellent reusability[6]. Niu et al. [57] synthesize the attapulgite-modified magnetic metal-organic frameworks (ATP@ $\mathrm{Fe}_{3} \mathrm{O}_{4} @ \mathrm{ZIF}-8$ ) as a sorbent to extract benzoylurea shows that the sorbent produced enrichment factors range 63.6-72.2.

Heavy metal is one type of contamination that is dangerous if it enters the body. One of the routes that heavy metals enter the body is through food. Habila et al. [58] synthesized magnetic nano sorbent from $\mathrm{Fe}_{3} \mathrm{O}_{4}$ nanoparticles with polyacrylamide using a solvothermal process. This process involves two steps: forming a carbon layer around the $\mathrm{Fe}_{3} \mathrm{O}_{4}$ and functionalization with amino groups. This 
sorbent is used for metals $\mathrm{Cr}$ (III), Co (II), Cd (II), Zn (II), and Pb (II) in food samples (eggplant, tomato, onion, and garlic). The validation analysis results using standard wheat gluten material showed that LOD is obtained with a 1-110 ng/l value with an RSD value of less than $10 \%$ and a recovery value of $97.0-100.00 \%$ [58]. The result showed that the magnetic nano sorbent could be applied to extract Cr (III), Co (II), Cd (II), Zn (II), and Pb (II) in food samples with high efficiency.

Shegefti et al. [59] synthesized the magnetic sorbent obtained by oxidative polymerization of thionine on $\mathrm{Fe}_{3} \mathrm{O}_{4} \quad\left(\mathrm{Fe}_{3} \mathrm{O}_{4} @ \mathrm{PTh}\right.$ ) nanoparticles for cobalt (II) extraction. Polythionine (PTh) is supposed to exhibit significant extraction efficiency because it has abundant amino moieties that absorb the metals ion and different organic halogen substances [60,61]. Cobalt measurements were carried out on water samples, canned fish, flour, spinach, black tea, and cocoa powder, with an accuracy value of $96.0-104.9 \%$ with a detection limit of $0.3 \mathrm{ng} / \mathrm{ml}$. The $\mathrm{Fe}_{3} \mathrm{O}_{4} @ \mathrm{PTh}$ sorbent shows that the sorbent can be reused because after being used for three adsorptiondesorption cycles, the performance of sorbent did not change significantly. The recovery obtained was more than $90 \%$ [59].

The MSPE method successfully extracts analytes in food samples, just as biological and environmental samples. One of the advantages of this method mentioned above is that the magnetic sorbent used can be reused because the performance of the sorbent did not change significantly after a few adsorption-desorption processes are carried out.

Table 2: Application of magnetic adsorbents in various samples

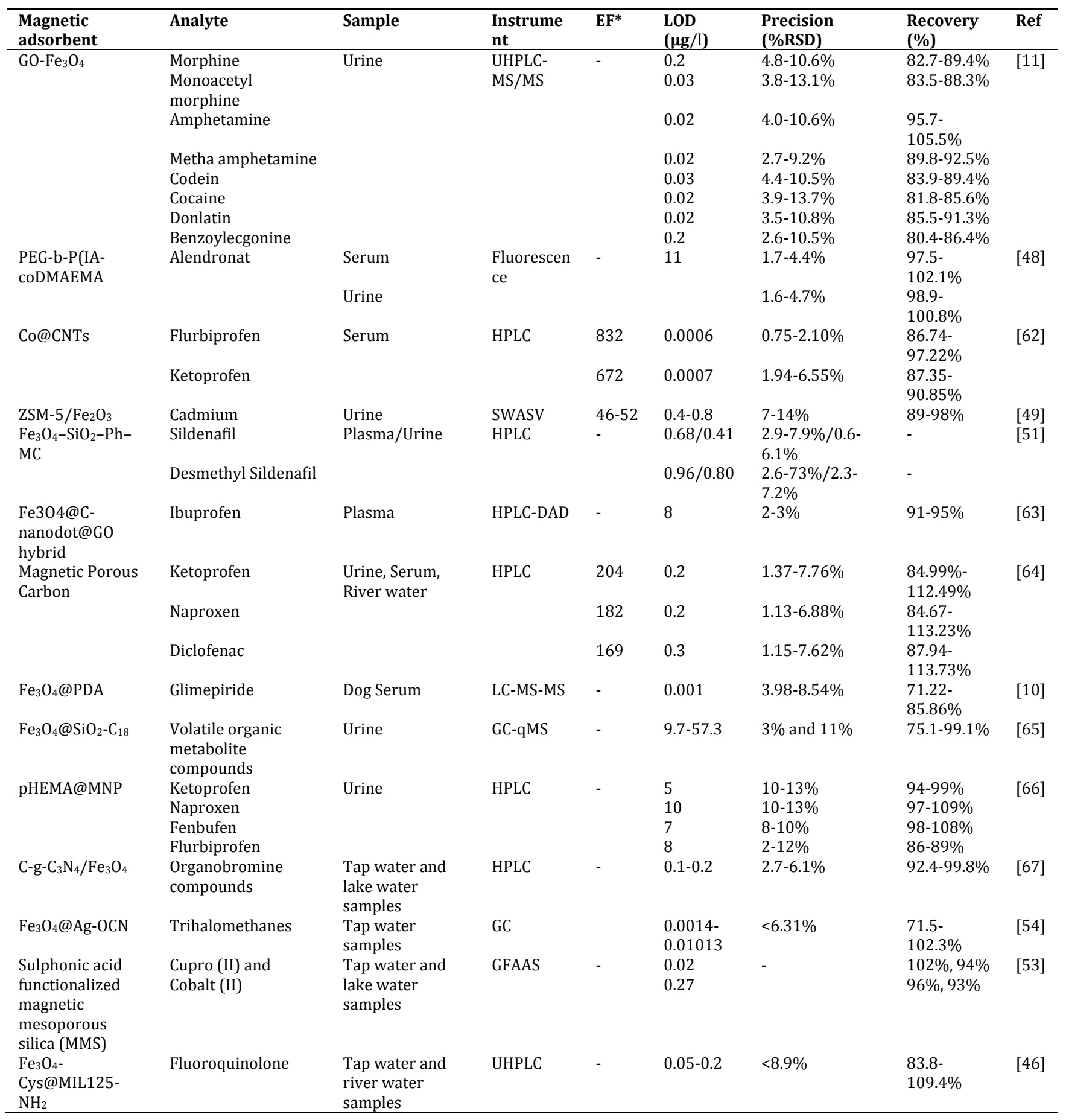




\begin{tabular}{|c|c|c|c|c|c|c|c|c|}
\hline $\begin{array}{l}\text { Magnetic } \\
\text { adsorbent }\end{array}$ & Analyte & Sample & $\begin{array}{l}\text { Instrume } \\
\text { nt }\end{array}$ & EF* $^{*}$ & $\begin{array}{l}\text { LOD } \\
(\mu \mathrm{g} / \mathrm{l})\end{array}$ & $\begin{array}{l}\text { Precision } \\
\text { (\%RSD) }\end{array}$ & $\begin{array}{l}\text { Recovery } \\
(\%)\end{array}$ & Ref \\
\hline $\begin{array}{l}\mathrm{Fe}_{3} \mathrm{O}_{4} @ \mathrm{fTiO}_{2-} \\
\mathrm{CMCD}\end{array}$ & Chlorobenzene & soil & GC-MS & - & $\begin{array}{l}0.009- \\
0.031 \\
\mu \mathrm{g} / \mathrm{kg}\end{array}$ & $\leq 5.4 \%$ & $\begin{array}{l}87.3- \\
104.3 \%\end{array}$ & [29] \\
\hline $\begin{array}{l}\text { Graphene oxide } \\
\text { and carbon } \\
\text { nanotubes }\end{array}$ & Glucocorticoid & $\begin{array}{l}\text { River water, lake } \\
\text { water, salt water }\end{array}$ & $\begin{array}{l}\text { HPLC- } \\
\text { MS/MS }\end{array}$ & $52-78$ & $\begin{array}{l}0.0075- \\
0.16 \mathrm{ng} / \mathrm{l}\end{array}$ & $<10.0 \%$ & $79.7-120 \%$ & [68] \\
\hline $\begin{array}{l}\text { Bacillus cereus SO- } \\
14 \text { immobilized- } \gamma \\
\text { Fe203 } \\
\text { nanoparticles }\end{array}$ & $\begin{array}{l}\text { Uranium (VI) dan } \\
\text { Thorium (IV) }\end{array}$ & Water samples & ICP-OES & - & $\begin{array}{l}0.008 \\
0.013 \\
\mathrm{ng} / \mathrm{l}\end{array}$ & $\leq 2.1 \%$ & - & [69] \\
\hline $\mathrm{Fe}_{3} \mathrm{O}_{4} @ \mathrm{PDA}-\mathrm{DES}$ & Sulphonyl urea & $\begin{array}{l}\text { Lake water and } \\
\text { drinking water }\end{array}$ & HPLC & $\begin{array}{l}495- \\
630\end{array}$ & $\begin{array}{l}0.0098- \\
0.110\end{array}$ & $1.2-3.6 \%$ & $\begin{array}{l}61.3- \\
108.6 \%\end{array}$ & [70] \\
\hline$\beta-\mathrm{CD} / \mathrm{MRGO}$ & Organochlorine & honey & GC-ECD & & $\begin{array}{l}0.52-3.21 \\
\mathrm{ng} / \mathrm{kg}\end{array}$ & $<8.1 \%$ & $\begin{array}{l}78.8- \\
116.2 \%\end{array}$ & [56] \\
\hline $\mathrm{Fe}_{3} \mathrm{O}_{4} @ \mathrm{MOF}-808$ & $\begin{array}{l}\text { Benzoylurea } \\
\text { insecticide }\end{array}$ & Tea and juice & HPLC & $\begin{array}{l}110- \\
120\end{array}$ & $0.04-0.15$ & $1.6-11.4 \%$ & $84.6-98.3 \%$ & [6] \\
\hline $\begin{array}{l}\text { MNP@ATED- } \\
\text { MSPE }\end{array}$ & $\begin{array}{l}\mathrm{Cd}(\mathrm{II}), \mathrm{Pb}(\mathrm{II}), \mathrm{Cu} \\
\text { (II) }\end{array}$ & Water; peanuts & GFAAS & & $\begin{array}{l}3.3-7.2 \\
\mathrm{ng} / \mathrm{l} ; 1.1- \\
1.5 \mu \mathrm{g} / \mathrm{kg}\end{array}$ & $<10 \%$ & $\begin{array}{l}80.5-114 \% \\
82.2-118 \%\end{array}$ & [72] \\
\hline $\begin{array}{l}\mathrm{ATP} @ \mathrm{Fe}_{3} \mathrm{O}_{4} @ \mathrm{ZIF}- \\
8\end{array}$ & Benzoylureas & Tea & HPLC & $\begin{array}{l}63.6- \\
72.3\end{array}$ & $0.7-3.2$ & $<10 \%$ & $\begin{array}{l}78.8- \\
114.3 \%\end{array}$ & [57] \\
\hline $\begin{array}{l}\text { (Zn-Al LDH)- } \\
\text { (PTh/DBSNa)- }\end{array}$ & Nikel (II) dan & $\begin{array}{l}\text { Apple, orange, } \\
\text { banana, meat, }\end{array}$ & MS-FAAS & 40 & $\begin{array}{l}1.3 \\
\mathrm{ng} / \mathrm{ml},\end{array}$ & $3.9-5.1 \%$ & $\begin{array}{l}98.3-99.6 \\
\%\end{array}$ & [73] \\
\hline $\mathrm{Fe} 304$ & Cadmium (II) & chicken, fish & & - & $0.7 \mathrm{ng} / \mathrm{ml}$ & $3.1-4.4 \%$ & $\begin{array}{l}97.6-99.0 \\
\%\end{array}$ & \\
\hline PS@MNPs & Pesticide & $\begin{array}{l}\text { Mango, Apricot, } \\
\text { peach, apple, } \\
\text { grape, tomato and } \\
\text { onion }\end{array}$ & GC-FID & $\begin{array}{l}230- \\
473\end{array}$ & $0.28-0.54$ & $2-5 \%$ & $90-103 \%$ & [14] \\
\hline
\end{tabular}

*EF: Enrichment Factor

\section{CONCLUSION}

The MSPE can be used in various biological, food, and environmental samples resulting in high enrichment factor value, good recovery, and the magnetic adsorbent has excellent reusability. The interaction between the analyte and magnetic sorbent was important in the extraction process using MSPE. The magnetic nanoparticle can be functionalized with organic, inorganic, and metal-organic framework compounds to obtain sorbent with great interaction and excellent extraction capability. When the MPSE method was applied in biological, environmental and food samples, the things must be considered desorption and extraction time, desorption solvent, $\mathrm{pH}$ used in the extraction process, and matrix effect. Moreover, the magnetic content of the magnetic sorbent must be concerned because the higher magnetic content showed the adsorbent would more easily be separated using an external magnetic field from the supernatant.

\section{ACKNOWLEDGEMENT}

The author thanks the Directorate of Research and Community Service Universitas Padjadjaran for supporting this research

\section{FUNDING}

Nil

\section{AUTHORS CONTRIBUTIONS}

All the authors have contributed equally.

\section{CONFLICT OF INTERESTS}

Declared none

\section{REFERENCES}

1. Li N, Jiang HL, Wang X, Wang X, Xu G, Zhang B, Wang L, Zhao R Lin J. Recent advances in graphene-based magnetic composites for magnetic solid-phase extraction. TrAC Trends Anal Chem. 2018;102:60-74. doi: 10.1016/j.trac.2018.01.009.

2. Das D, Gupta U, Das AK. Recent developments in solid-phase extraction in elemental speciation of environmental samples with special reference to aqueous solutions. TrAC Trends Anal Chem. 2012;38:163-71. doi: 10.1016/j.trac.2011.01.020.

3. Jiang HL, Li N, Cui L, Wang X, Zhao RS. Recent application of magnetic solid-phase extraction for food safety analysis. TrAC Trends Anal Chem. 2019;120. doi: 10.1016/j.trac.2019.115632, PMID 115632.

4. Yu X, Lim CYX, Dong B, Hadinoto K. Development of magnetic solid-phase extraction platform for the purification of bioactive $\gamma$-glutamyl peptides from garlic (Allium sativum). LWT. 2020;127. doi: 10.1016/j.lwt.2020.109410, PMID 109410.

5. Herrero Latorre C, Barciela Garcia J, Garcia Martin S, Pena Crecente RM, Otarola Jimenez J. Magnetic solid-phase extraction using carbon nanotubes as sorbents: a review. Anal Chim Acta. 2015;892:10-26. doi: 10.1016/j.aca.2015.07.046, PMID 26388472

6. Jia Y, Wang Y, Yan M, Wang $\mathrm{Q}, \mathrm{Xu} \mathrm{H}$, Wang $\mathrm{X}$, Zhou H, Hao Y, Wang M. Fabrication of iron oxide@MOF-808 as a sorbent for magnetic solid-phase extraction of benzoylurea insecticides in tea beverages and juice samples. J Chromatogr A 2020;1615:460766. doi: 10.1016/j.chroma.2019.460766.

7. Liu JF, Yuan BF, Feng YQ. Determination of hexanal and heptanal in human urine using magnetic solid-phase extraction coupled with in-situ derivatization by high-performance liquid 
chromatography. Talanta. 2015;136:54-9. doi: 10.1016/ j.talanta.2015.01.003, PMID 25702985.

8. Zou J, Guo M, Feng Y, Yang M, Cao Y, Zhu D, Yu Y. Voltammetric determination of nonylphenol using a glassy carbon electrode modified with a nanocomposite consisting of CTAB, Fe304 nanoparticles and reduced graphene oxide. Microchim Acta. 2017;184(2):533-40. doi: 10.1007/s00604-016-2047-5.

9. Jie M, Lin H, He Z, Liu H, Li H, Lin JM. An on-chip intestine-liver model for multiple drugs absorption and metabolism behavior simulation. Sci China Chem. 2018;61(2):236-42. doi: 10.1007/s11426-017-9167-0.

10. Zhu J, Li Y, Xiang Y, Zhou L, Li Y. Magnetic solid-phase extraction followed with LC-MS/MS for determination of glimepiride in beagle dog plasma and its application to bioequivalence study. J Pharm Biomed Anal. 2020;184:113180. doi: 10.1016/ j.jpba.2020.113180.

11. Lu Q Guo H, Zhang Y, Tang X, Lei W, Qi R, Chu J, Li D, Zhao Q. Graphene oxide-Fe304 nanocomposite magnetic solid-phase extraction followed by UHPLC-MS/MS for highly sensitive determination of eight psychoactive drugs in urine samples. Talanta. 2020;206:120212. doi: 10.1016/j.talanta.2019.120212.

12. Khezeli T, Daneshfar A. Dispersive micro-solid-phase extraction of dopamine, epinephrine and norepinephrine from biological samples based on green deep eutectic solvents and Fe304@MIL-100 (Fe) core-shell nanoparticles grafted with pyrocatechol. RSC Adv. 2015;5(80):65264-73. doi: 10.1039/C5RA08058D.

13. Wu J, Zhao H, Xiao D, Chuong PH, He J, He H. Mixed hemimicelles solid-phase extraction of cephalosporins in biological samples with ionic liquid-coated magnetic graphene oxide nanoparticles coupled with high-performance liquid chromatographic analysis. J Chromatogr A. 2016;1454:1-8. doi: 10.1016/j.chroma.2016.05.071, PMID 27266334.

14. Sattari Dabbagh M, Farajzadeh MA. Introduction of a new procedure for the synthesis of polysulfone magnetic nanoparticles and their application in magnetic solid-phase extraction for the extraction of some pesticides from fruit and vegetable juices. Microchem J. 2020;158. doi: 10.1016/j.microc.2020.105238, PMID 105238.

15. Costa dos Reis L, Vidal L, Canals A. Graphene oxide/Fe304 as sorbent for magnetic solid-phase extraction coupled with liquid chromatography to determine 2,4,6-trinitrotoluene in water samples. Anal Bioanal Chem. 2017;409(10):2665-74. doi: 10.1007/s00216-017-0211-3, PMID 28188348.

16. Kilınc E, Celik KS, Bilgetekin H. $\gamma$-Fe2O3 magnetic nanoparticle functionalized with carboxylated multi-walled carbon nanotube for magnetic solid-phase extractions and determinations of Sudan dyes and Para Red in food samples. Food Chem. 2018;242:533-7. doi: 10.1016/j.foodchem.2017.09.039, PMID 29037726.

17. Ozdogan N, Kapukıran F, Ozturk Er E, Bakırdere S. Magnetic cobalt particle-assisted solid-phase extraction of tellurium prior to its determination by slotted quartz tube-flame atomic absorption spectrophotometry. Environ Monit Assess. 2019;191(6):339. doi: 10.1007/s10661-019-7490-4, PMID 31053958.

18. Monsef Khoshhesab Z, Najafi N. Magnetic solid-phase extraction to preconcentrate trace amounts of gold (III) using nickel ferrite magnetic nanoparticles. Int J Environ Anal Chem. 2017;97(13):1237-52. doi: 10.1080/03067319.2017.1400024.

19. Geng Y, Ding M, Chen H, Li HF, Lin JM. Preparation of hydrophilic carbon-functionalized magnetic microspheres coated with chitosan and application in solid-phase extraction of bisphenol a in aqueous samples. Talanta. 2012;89:189-94. doi: 10.1016/j.talanta.2011.12.015, PMID 22284479.

20. Chen L, Wang T, Tong J. Application of derivatized magnetic materials to the separation and the preconcentration of pollutants in water samples. TrAC Trends Anal Chem. 2011;30(7):1095-108. doi: 10.1016/j.trac.2011.02.013.

21. Huo SH, An HY, Yu J, Mao XF, Zhang Z, Bai L, Huang YF, Zhou PX. Pyrolytic in situ magnetization of metal-organic framework MIL-100 for magnetic solid-phase extraction. J Chromatogr A. 2017;1517:18-25. doi: 10.1016/j.chroma.2017.08.039, PMID 28847581.

22. Hernandez Hernandez AA, Alvarez Romero GA, Castaneda Ovando A, Mendoza Tolentino Y, Contreras Lopez E, Galan Vidal
CA, Paez Hernandez ME. Optimization of microwavesolvothermal synthesis of $\mathrm{Fe} 304$ nanoparticles. Coating, modification, and characterization. Mater Chem Phys. 2018;205:113-9. doi: 10.1016/j.matchemphys.2017.11.009.

23. Zaki T, Saed D, Aman D, Younis SA, Moustafa YM. Synthesis and characterization of MFe204 sulfur nanoadsorbents. J Sol Gel Sci Technol. 2013;65(2):269-76. doi: 10.1007/s10971-012-2933-1.

24. Santoyo Salazar J, Perez L, De Abril O, Truong Phuoc L, Ihiawakrim D, Vazquez M, Greneche J, Begin-Colin S, Pourroy G. Magnetic iron oxide nanoparticles in 10-40 nm range: composition in terms of magnetite/maghemite ratio and effect on the magnetic properties. Chem Mater. 2011;23(6):1379-86. doi: $10.1021 / \mathrm{cm} 103188 \mathrm{a}$.

25. Salvador M, Gutierrez G, Noriega S, Moyano A, Blanco Lopez $\mathrm{MC}$, Matos M. Microemulsion synthesis of superparamagnetic nanoparticles for bioapplications. Int J Mol Sci. 2021;22(1). doi: 10.3390/ijms22010427, PMID 33406682

26. Lee H, Dellatore SM, Miller WM, Messersmith PB. Musselinspired surface chemistry for multifunctional coatings. Science. 2007;318(5849):426-30. doi: 10.1126/ science.1147241, PMID 17947576.

27. Li JY, Long XY, Yin HX, Qiao JQ, Lian HZ. Magnetic solid-phase extraction based on polydopamine-coated $\mathrm{Fe} 304$ nanoparticles absorbent for the determination of bisphenol $A$ tetrabromobisphenol A, 2,4,6-tribromophenol, and (S)-1,1'-bi2-naphthol in environmental waters by HPLC. J Sep Sci. 2016;39(13):2562-72. doi: 10.1002/jssc.201600231, PMID 27144726.

28. Zhang J, Liu D, Meng X, Shi Y, Wang R, Xiao D, He H. Solid-phase extraction based on porous magnetic graphene oxide/ $\beta$ cyclodextrine composite coupled with high-performance liquid chromatography for determination of antiepileptic drugs in plasma samples. J Chromatogr A. 2017;1524:49-56. doi: 10.1016/j.chroma.2017.09.074, PMID 29030037.

29. Zhang J, Gan N, Chen S, Pan M, Wu D, Cao Y. B-cyclodextrin functionalized Meso-/Macroporous magnetic titanium dioxide adsorbent as extraction material combined with gas chromatography-mass spectrometry for the detection of chlorobenzenes in soil samples. J Chromatogr A. 2015;1401:2432. doi: 10.1016/j.chroma.2015.04.057, PMID 25990351.

30. Liu Q, Shi J, Wang T, Guo F, Liu L, Jiang G. Hemimicelles/admicelles supported on magnetic graphene sheets for enhanced magnetic solid-phase extraction. J Chromatogr A. 2012;1257:1-8. doi: 10.1016/ j.chroma.2012.08.028, PMID 22921358.

31. Pashaei Y, Daraei B, Shekarchi M. Magnetic-dispersive solid phase extraction based on graphene oxide-Fe 3 l 0 nanocomposites followed by high-performance liquid chromatography-fluorescence for the preconcentration and determination of terazosin hydrochloride in human plasma. J Chromatogr Sci. 2020;58(2):178-86. doi: 10.1093/chromsci/bmz085, PMID 31746326.

32. Li SY, Petrikovics I, Yu JC. Development of magnetic carbon nanotubes for dispersive micro solid-phase extraction of the cyanide metabolite, 2-aminothiazoline-4-carboxylic acid, in biological samples. J Chromatogr B. 2019;1109:67-75. doi: 10.1016/j.jchromb.2019.01.020.

33. Zhang W, Yan Z, Gao J, Tong P, Liu W, Zhang L. Metal-organic framework UiO-66 modified magnetite@silica core-shell magnetic microspheres for magnetic solid-phase extraction of domoic acid from shellfish samples. J Chromatogr A. 2015;1400:10-8. doi: 10.1016/j.chroma.2015.04.061, PMID 25997847.

34. Huo SH, Yan XP. Facile magnetization of metal-organic framework MIL-101 for magnetic solid-phase extraction of polycyclic aromatic hydrocarbons in environmental water samples. Analyst. 2012;137(15):3445-51. doi: 10.1039/c2an35429b, PMID 22695791.

35. Szejtli J. Cyclodextrin technology. Springer-science+business media; 2013.

36. Guo Y, Guo S, Li J, Wang E, Dong S. Cyclodextrin-graphene hybrid nanosheets as enhanced sensing platform for ultrasensitive determination of carbendazim. Talanta. 2011;84(1):60-4. doi: 10.1016/j.talanta.2010.12.007, PMID 21315898. 
37. Wang Y, Wang S, Niu H, Ma Y, Zeng T, Cai Y, Meng Z. Preparation of polydopamine coated $\mathrm{Fe}_{3} \mathrm{O}_{4}$ nanoparticles and their application for the enrichment of polycyclic aromatic hydrocarbons from environmental water samples. J Chromatogr A. 2013;1283:20-6. doi: 10.1016/j.chroma.2013.01.110, PMID 23422895.

38. Zhou Z, Liu R. Fe304@polydopamine and derived Fe304@carbon core-shell nanoparticles: comparison in adsorption for cationic and anionic dyes. Colloids and Surfaces A: Physicochemical and Engineering Aspects. 2017;522:260-5. doi: 10.1016/j.colsurfa.2017.02.063.

39. Merino F, Rubio S, Pérez-Bendito D. Mixed aggregate-based acid-induced cloud-point extraction and ion-trap liquid chromatography-mass spectrometry for the determination of cationic surfactants in sewage sludge. J Chromatogr A. 2003;998(1-2):143-54. doi: 10.1016/s0021-9673(03)00565-X, PMID 12862380.

40. Han Q, Wang Z, Xia J, Chen S, Zhang X, Ding M. Facile and tunable fabrication of Fe304/graphene oxide nanocomposites and their application in the magnetic solid-phase extraction of polycyclic aromatic hydrocarbons from environmental water samples. Talanta. 2012;101:388-95. doi: 10.1016/j.talanta.2012.09.046, PMID 23158339.

41. Hanifah MFR, Jaafar J, Othman MHD, Ismail AF, Rahman MA, Yusof N, Salleh WNW, Aziz F. Facile synthesis of highly favorable graphene oxide: effect of oxidation degree on the structural, morphological, thermal and electrochemical properties. Materialia. 2019;6. doi: 10.1016/j.mtla.2019.100344, PMID 100344.

42. El-Sheikh AH, Qawariq RF, Abdelghani JI. Adsorption and magnetic solid-phase extraction of NSAIDs from pharmaceutical wastewater using magnetic carbon nanotubes: effect of sorbent dimensions, magnetite loading and competitive adsorption study. Environ Technol Innov. 2019;16. doi: 10.1016/j.eti.2019.100496, PMID 100496.

43. Mashhadizadeh $\mathrm{MH}$, Amoli-Diva M. Atomic absorption spectrometric determination of $\mathrm{Al} 3+$ and $\mathrm{Cr} 3+$ after preconcentration and separation on 3-mercaptopropionic acid modified silica coated-Fe304 nanoparticles. J Anal At Spectrom. 2013;28(2):251-8. doi: 10.1039/c2ja30286a.

44. Fan YH, Zhang SW, Qin SB, Li XS, Zhang Y, Qi SH. Facile preparation of hexadecyl-functionalized magnetic core-shell microsphere for the extraction of polychlorinated biphenyls in environmental waters. Anal Bioanal Chem. 2017;409(13):3337-46. doi: 10.1007/s00216-017-0278-x, PMID 28283719.

45. Caon NB, Cardoso CdS, Faita FL, Vitali L, Parize AL. Magnetic solid-phase extraction of triclosan from water using noctadecyl modified silica-coated magnetic nanoparticles. J Environ Chem Eng. 2020;8(4). doi: 10.1016/j.jece.2020.104003, PMID 104003.

46. Lian L, Zhang X, Hao J, Lv J, Wang X, Zhu B, Lou D. Magnetic solid-phase extraction of fluoroquinolones from water samples using titanium-based metal-organic framework functionalized magnetic microspheres. J Chromatogr A. 2018;1579:1-8. doi: 10.1016/j.chroma.2018.10.019, PMID 30352707.

47. Tian J, Xu J, Zhu F, Lu T, Su C, Ouyang G. Application of nanomaterials in sample preparation. J Chromatogr A. 2013;1300:2-16. doi: 10.1016/j.chroma.2013.04.010, PMID 23611621.

48. Niaei N, Samadi A, Hamishehkar H, Ghorbani M. Development of terbium-sensitized fluorescence method for the determination of alendronate in biological samples followed by magnetic solid-phase extraction. Microchem J. 2019;146:88894. doi: 10.1016/j.microc.2019.01.076.

49. Baile P, Vidal L, Canals A. Magnetic dispersive solid-phase extraction using ZSM-5 zeolite/Fe203 composite coupled with screen-printed electrodes based electrochemical detector for determination of cadmium in urine samples. Talanta. 2020;220:121394. doi: 10.1016/j.talanta.2020.121394.

50. Ershadi S, Jouyban A, Molavi O, Shayanfar A. Development of a terbium-sensitized fluorescence method for analysis of silibinin. J AOAC Int. 2017;100(3):686-91. doi: 10.5740/jaoacint.16-0208, PMID 28118130.

51. Tang M, Wang Q, Jiang M, Xu L, Shi ZG, Zhang T, Liu Y. Magnetic solid-phase extraction based on methylcellulose coated-Fe
304-SiO2-phenyl for HPLC-DAD analysis of sildenafil and its metabolite in biological samples. Talanta. 2014;130:427-32. doi: 10.1016/j.talanta.2014.07.006, PMID 25159431.

52. Schultz MM. Chemicals of environmental concern. In: Encyclopedia of toxicology. 3rd ed; 2014.

53. Shah SM, Makhdoom AR, Su X, Faheem M, Irfan M, Irfan M, Wang G, Gao Y. Synthesis of sulphonic acid-functionalized magnetic mesoporous silica for $\mathrm{Cu}$ (II) and $\mathrm{Co}(\mathrm{II})$ adsorption. Microchem J. 2019;151. doi: 10.1016/j.microc.2019.104194, PMID 104194.

54. Li QL, Guo SF, Zhang Y, Wo R, Zhao RS, Jiang W. Silver-organic coordination networks for magnetic solid-phase extraction of trihalomethanes from environmental water samples: experimental and theoretical calculation study. J Hazard Mater. 2020;396:122741. doi: 10.1016/j.jhazmat.2020.122741.

55. Badan Pengawas Obat dan Makanan. Batas maksimum cemaran logam berat dalam pangan olahan. PerBPOM Nomor 23 tahun. 2017;2017:10-1.

56. Mahpishanian $S$, Sereshti $H$. One-step green synthesis of $\beta$ cyclodextrin/iron oxide-reduced graphene oxide nanocomposite with high supramolecular recognition capability: application for vortex-assisted magnetic solid-phase extraction of organochlorine pesticides residue from honey samples. J Chromatogr A. 2017;1485:32-43. doi: 10.1016/j.chroma.2017.01.035, PMID 28104237.

57. Niu M, Li Z, He W, Zhou W, Lu R, Li J, Gao H, Zhang S, Pan C. Attapulgite modified magnetic metal-organic frameworks for magnetic solid-phase extraction and determinations of benzoylurea insecticides in tea infusions. Food Chem. 2020;317:126425. doi: 10.1016/j.foodchem.2020.126425.

58. Habila MA, Alothman ZA, El-Toni AM, Al-Tamrah SA, Soylak M, Labis JP. Carbon-coated Fe304 nanoparticles with surface amido groups for magnetic solid-phase extraction of $\operatorname{Cr}(\mathrm{III})$, $\mathrm{Co}(\mathrm{II}), \mathrm{Cd}(\mathrm{II}), \mathrm{Zn}(\mathrm{II})$ and $\mathrm{Pb}(\mathrm{II})$ prior to their quantitation by ICP-MS. Microchim Acta. 2017;184(8):2645-51. doi: 10.1007/s00604-017-2283-3.

59. Shegefti S, Mehdinia A, Shemirani F. Preconcentration of cobalt(II) using polythionine-coated Fe304 nanocomposite prior its determination by AAS. Microchim Acta. 2016;183(6):1963-70. doi: 10.1007/s00604-016-1837-0.

60. Owino JHO, Arotiba OA, Hendricks N, Songa EA, Jahed N, Waryo TT, Ngece RF, Baker PG, Iwuoha EI. Electrochemical immunosensor based on polythionine/gold nanoparticles for the determination of aflatoxin $B_{1}$. Sensors (Basel). 2008;8(12):8262-74. doi: 10.3390/s8128262, PMID 27873987.

61. Wang F, Yuan R, Chai Y. A new amperometric biosensor for hydrogen peroxide determination based on HRP-nanogold-PTHnanogold-modified carbon paste electrodes. Eur Food Res Technol. 2007;225(1):95-104. doi: 10.1007/s00217-006-0386-X.

62. Wu W, Lin F, Yang X, Wang B, Lu X, Chen Q, Ye F, Zhao S. Facile synthesis of magnetic carbon nanotubes derived from ZIF-67 and application to magnetic solid-phase extraction of profens from human serum. Talanta. 2020;207:120284. doi: 10.1016/j.talanta.2019.120284.

63. Yuvali D, Narin I, Soylak M, Yilmaz E. Green synthesis of magnetic carbon nanodot/graphene oxide hybrid material (Fe304@C-nanodot@GO) for magnetic solid-phase extraction of ibuprofen in human blood samples prior to HPLC-DAD determination. J Pharm Biomed Anal. 2020;179:113001. doi: 10.1016/j.jpba.2019.113001.

64. Han X, Chen J, Li Z, Qiu H. Combustion fabrication of magnetic porous carbon as a novel magnetic solid-phase extraction adsorbent for the determination of non-steroidal antiinflammatory drugs. Anal Chim Acta. 2019;1078:78-89. doi: 10.1016/j.aca.2019.06.022, PMID 31358231.

65. Qiao Z, Perestrelo R, Reyes Gallardo EM, Lucena R, Cardenas S, Rodrigues J, Câmara JS. Octadecyl functionalized core-shell magnetic silica nanoparticle as a powerful nanocomposite sorbent to extract urinary volatile organic metabolites. J Chromatogr A. 2015;1393:18-25. doi: 10.1016/j.chroma.2015.03.026, PMID 25818559.

66. Fresco-Cala B, Gálvez-Vergara A, Cárdenas S. Preparation, characterization and evaluation of hydrophilic polymers containing magnetic nanoparticles and amine-modified carbon 
nanotubes for the determination of anti-inflammatory drugs in urine samples. Talanta. 2020;218:121124. doi: 10.1016/j.talanta.2020.121124.

67. Wang M, Yuan H, Deng W, Bi W, Yang X. A Taiji-principledesigned magnetic porous $\mathrm{C}$-doped graphitic carbon nitride for environment-friendly solid-phase extraction of pollutants from water samples. J Chromatogr A. 2015;1412:12-21. doi: 10.1016/j.chroma.2015.08.011, PMID 26278354.

68. Huang Y, Li Y, Luo Q, Huang X. One-step preparation of functional groups-rich graphene oxide and carbon nanotubes nanocomposite for efficient magnetic solidphase extraction of glucocorticoids in environmental waters. Chem Eng J. 2021;406. doi: 10.1016/j.cej.2020.126785, PMID 126785.

69. Ozdemir S, Kilınc E, Yalcin MS, Soylak M, Sen F. A new magnetized thermophilic bacteria to preconcentrate uranium and thorium from environmental samples through magnetic solid-phase extraction. J Pharm Biomed Anal. 2020;186:113315. doi: 10.1016/j.jpba.2020.113315.

70. Wang DD, Zhao Y, Ou yang MN, Guo HM, Yang ZH. Magnetic polydopamine modified with deep eutectic solvent for the magnetic solid-phase extraction of sulfonylurea herbicides in water samples. J Chromatogr A. 2019;1601:53-9. doi: 10.1016/j.chroma.2019.05.011, PMID 31130226.
71. Nasir ANM, Yahaya N, Zain NNM, Lim V, Kamaruzaman S, Saad B, Nishiyama N, Yoshida N, Hirota Y. Thiol-functionalized magnetic carbon nanotubes for magnetic micro-solid phase extraction of sulfonamide antibiotics from milks and commercial chicken meat products. Food Chem. 2019;276:45866. doi: 10.1016/j.foodchem.2018.10.044, PMID 30409620.

72. Huang Y, Peng J, Huang X. Allylthiourea functionalized magnetic adsorbent for the extraction of cadmium, copper and lead ions prior to their determination by atomic absorption spectrometry. Mikrochim Acta. 2019;186(2):51. doi: 10.1007/s00604-018-3101-2, PMID 30617620.

73. Rajabi M, Abolhosseini M, Hosseini-Bandegharaei A, Hemmati M, Ghassab N. Magnetic dispersive micro-solid phase extraction merged with micro-sampling flame atomic absorption spectrometry using (Zn-Al LDH)-(PTh/DBSNa)-Fe3O4 nano sorbent for effective trace determination of nickel(II) and cadmium(II) in food samples. Microchem J. 2020;159. doi: 10.1016/j.microc.2020.105450, PMID 105450.

74. Majidi SM, Hadjmohammadi MR. Development of magnetic dispersive micro-solid phase extraction based on magnetic agarose nanoparticles and deep eutectic solvents for the isolation and pre-concentration of three flavonoids in edible natural samples. Talanta. 2021;222:121649:121649. doi: 10.1016/j.talanta.2020.121649. 